\title{
Identificatin and quantiative analysis of amyrins in Humulus lupulus $\mathrm{L}$.
}

\author{
Kamila Rokicka, Magdalena Wojciak-Kosior ${ }^{*}$
}

Departament of Chemistry, Medicinal University in Lublin, Chodzki 4a, 20-093 Lublin

\begin{tabular}{|c|c|}
\hline ARTICLE INFO & ABSTRACT \\
\hline $\begin{array}{l}\text { Received } 20 \text { August } 2014 \\
\text { Accepted } 26 \text { August } 2014\end{array}$ & $\begin{array}{l}\text { In the paper, the identification and quantification of } \alpha \text { - and } \beta \text {-amyrin in five varieties } \\
\text { of Humulus lupulus is described. The plant samples were extracted with ethyl acetate }\end{array}$ \\
\hline $\begin{array}{l}\text { Keywords: } \\
\text { amyrin, } \\
\text { Humulus lupulus, } \\
\text { triterpenes. }\end{array}$ & $\begin{array}{l}\text { detection. The separation was achieved on } \mathrm{RP} 18 \text { column, at } 2 \mathrm{~mL} / \mathrm{min} \text { flow rate and at } \\
\text { temperature of } 35^{\circ} \mathrm{C} \text {. Acetonitrile was used as a mobile phase. The established calibration } \\
\text { curves and the other validation parameters: linearity (correlation coefficient } \mathrm{r}>0.9988 \text { ) } \\
\text { and precision (RSD values ranged from } 0.14 \text { to } 1.81 \% \text { ) were found to be satisfactory for } \\
\text { the proposed method. The content of } \alpha \text { - and } \beta \text {-amyrin strongly depended on varieties of } \\
\text { H. lupulus and amounted from } 72.7 \text { to } 232.5 \mu \mathrm{g} / \mathrm{g} \text { and from } 77.9 \text { to } 176.9 \mu \mathrm{g} / \mathrm{g} \text { of dry plant } \\
\text { material, respectively. }\end{array}$ \\
\hline
\end{tabular}

\section{INTRODUCTION}

Humulus lupulus L. (Cannabaceae) popularly known as a hop is a flowering plant, native to Europe, western Asia and North America. Its female inflorescences are commonly called cones. In Poland, it commonly occurs on the moist thickets, alder and alluvial forests, and in old parks, gardens and slums [6]. The plant is well known in the brewing industry because it provides the characteristic aroma and flavor and is used to preserve beer. Moreover, the cones extracts are used in medicine for ulcers and chronic wounds, due to strong antibacterial and antifungal action [3]. They are also applied during inflammation of face and scalp for people with allergy, especially for skin with seborrhea and acne. The hop alleviates hyperactivity and is recommended as a mild sedative in sleeping disorders $[5,11]$. In recent years, the estrogenic, antioxidant and potential anticancer properties was also reported $[1,2,7,8]$

The therapeutic activity of $H$. lupulus is related to a presence of biologically active substances such as: terpenes, chalcones, flavonol glycosides, aromatic resin (lupulin), volatile oil, bitter acids and catechins [10,12].

$\beta$ - and $\alpha$-amyrin (Fig. 1) belong to triterpenoids which widely exist in food, medicinal herbs and other plants. There are a lot of reports about their antitumor, anti-inflammatry, analgesic, antiplatelet and antibacterial effect $[4,9,13]$.

Corresponding author

e-mail: kosiorma@wp.pl
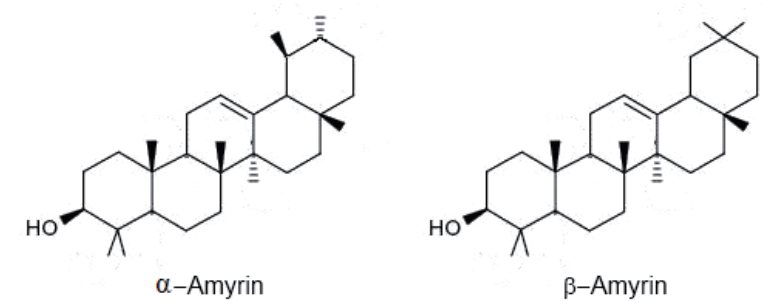

Figure 1. The chemical structure of $\alpha$-amyrin and $\beta$-amyrin

The objective of our investigation was analysis of extract from different varieties of $H$. lupulus for presence of amyrins. These triterpenes can influence on anti-inflammatory and antioxidant activity of extract from H. lupulus.

\section{MATERIALS AND METHODS}

\section{Chemicals}

$\beta$ - and $\alpha$-amyrin standards were purchased from Sigma (St. Louis, MO, USA). The purities of standards were 98.5\%. HPLC-grade methanol and acetonitrile were from Merck (Darmstadt, Germany). Water was deionized and purified by ULTRAPURE Milipore Direct-Q ${ }^{\circledR}$ 3UV-R (Merck).

\section{Standard and sample preparation}

Stock solutions of $\alpha$ - and $\beta$-amyrin were prepared by dissolving $0.48 \mathrm{mg} \alpha$-amyrin and $0.57 \mathrm{mg} \beta$-amyrin in $10 \mathrm{~mL}$ of methanol (final concentrations were: $48 \mu \mathrm{g} / \mathrm{mL}$ and 
$57 \mu \mathrm{g} / \mathrm{mL}$, respectively). Standard working solutions were prepared by dilution of the stock solutions with methanol.

Five varieties of $H$. lupulus cones: magnost, magnum, junga, sybilla and lubelski were collected by IUNG from Puławy (October 2013). Plant material was pulverized and accurately weighted $(5 \mathrm{~g})$. Samples were extracted two times with $2 \times 25 \mathrm{~mL}$ portion of ethyl acetate in ultrasonic bath at temperature of $35^{\circ} \mathrm{C}(2 \times 30 \mathrm{~min}$. $)$. The obtained extracts were combined, evaporated to dryness, dissolved in small amount of methanol and then filtered to measuring flask. Finally, the volume was made up by methanol to $10 \mathrm{~mL}$.

\section{Chromatographic conditions}

Quantitative HPLC analysis was conducted using VWR Hitachi Chromaster 600 chromatograph (Merck, Darmstadt, Germany) with pump (5160), a degasser, thermostat (5310), autosampler (5260), DAD detector (5430) and EZChrom Elite software.

The extracts were separated on LiChrospher 100 (Merck, Darmstadt, Germany) C18 reversed-phase column $(25 \mathrm{~cm} \times$ $4.0 \mathrm{~mm}$ i.d., $5 \mu \mathrm{m}$ particle size) at flow rate of $2.0 \mathrm{~mL} / \mathrm{min}$ with use of isocratic elution. Mobile phase consisted of acetonitrile. The temperature of autosampler and thermostat was $35^{\circ} \mathrm{C}$. The quantification was conducted at $200 \mathrm{~nm}$.

\section{RESULTS AND DISCUSSION}

Chromatographic conditions to determine $\alpha$ - and $\beta$-amyrin were established experimentally. Both amyrins have a strong retention on octadecyl silica, thus the solvents with high elution strength such as methanol, acetonitrile or propanol should be used for their analysis. The best shape of chromatographic peaks as well as sensitivity of determination were obtained for pure acetonitrile. Under conditions described above, amyrins were well separated from the other components of the samples (Fig. 2). Peaks were identified by comparison of retention times and UV spectra with those of the corresponding standards. Times of retention for $\beta$-amyrin and $\alpha$-amyrin were: $17.14 \pm 0.12 \mathrm{~min}$ and $19.14 \pm 0.18 \mathrm{~min}$, respectively.

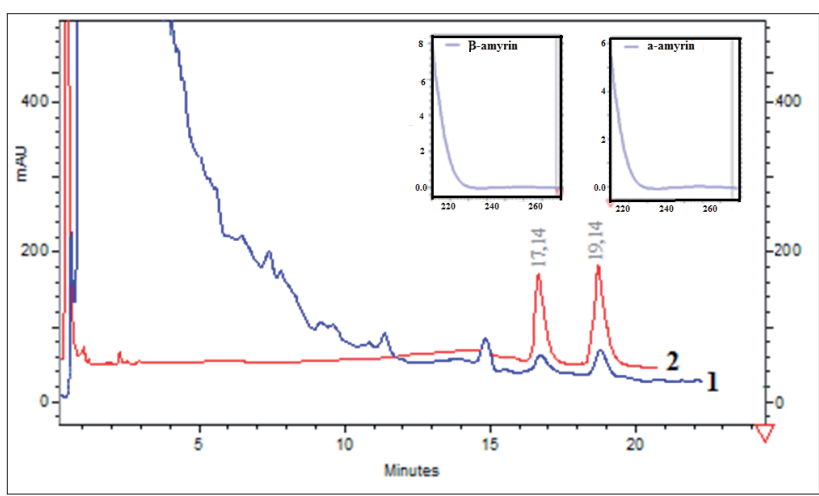

Figure 2. The chromatogram of extract from $H$. lupulus (1) and standard of $\alpha$-amyrin and $\beta$-amyrin (2)

The calibration curves were constructed on the basis of peak areas $(n=3)$. The obtained linear regression equations and the validation parameters such as: linearity, precision expressed as a relative standard deviation, limit of detection and quantification are summarized in Table 1. Samples of extracts were analyzed in triplicate and the amounts of triterpenes were calculated from the calibration plot. The data were analyzed by linear regression equation.

Table 1. The obtained validation parameters

\begin{tabular}{|c|c|c|}
\hline Component & a-amyrin & $\beta$-amyrin \\
\hline Regression equation & $\begin{array}{c}y=17269701 x- \\
140355\end{array}$ & $\begin{array}{c}y=20683915 x- \\
106522\end{array}$ \\
\hline Correlation coefficient & $r=0.9988$ & $r=0.9993$ \\
\hline RSD values & $0.14-1.70 \%$ & $0.30-1.81 \%$ \\
\hline Limit of detection (LOD) $(\mu \mathrm{g} / \mathrm{mL})$ & 0.49 & 1.12 \\
\hline Limit of quantification ( $\mathrm{LOQ})(\mu \mathrm{g} / \mathrm{mL})$ & 1.49 & 3.39 \\
\hline
\end{tabular}

The both investigated compounds were detected in cones of all varieties of $H$. lupulus. The content of $\alpha$ - and $\beta$-amyrin found in cones of $H$. lupulus using the presented method were from 72.7 to $232.5 \mu \mathrm{g} / \mathrm{g}$ and from 77.9 to $176.9 \mu \mathrm{g} / \mathrm{g}$ of dry plant material, respectively. The obtained results are presented in Table 2. The high variation of amyrin content was observed depending on varieties. The highest total amount of investigated triterpenes was found in var. junga while the lowest concentration was determined in var. magnost (Fig.3).

Table 2. The results of quantification of investigated triterpenes in H. lupulus L.

\begin{tabular}{|l|c|c|}
\hline \multicolumn{1}{|c|}{ Plant material } & $\begin{array}{c}\text { a-amyrin } \\
(\mu \mathrm{g} / \mathrm{g} \text { of dry plant } \\
\text { material } \pm \mathrm{SD})\end{array}$ & $\begin{array}{c}\beta \text {-amyrin } \\
(\mu \mathrm{g} / \mathrm{g} \text { of dry plant } \\
\text { material } \pm \mathrm{SD})\end{array}$ \\
\hline H. lupulus var. magnost & $72.7 \pm 1.2$ & $80.2 \pm 0.8$ \\
\hline H. lupulus var. magnum & $116.7 \pm 0.5$ & $140.8 \pm 0.59$ \\
\hline H. lupulus var. junga & $232.5 \pm 1.0$ & $176.9 \pm 1.36$ \\
\hline H. lupulus var. sybilla & $143.4 \pm 2.9$ & $77.9 \pm 1.30$ \\
\hline H. lupulus var. lubelski & $151.2 \pm 2.4$ & $80.7 \pm 0.80$ \\
\hline
\end{tabular}

The investigated compounds may have a positive influence, directly or indirectly by synergistic action, on its antiinflammatory and antioxidant properties.

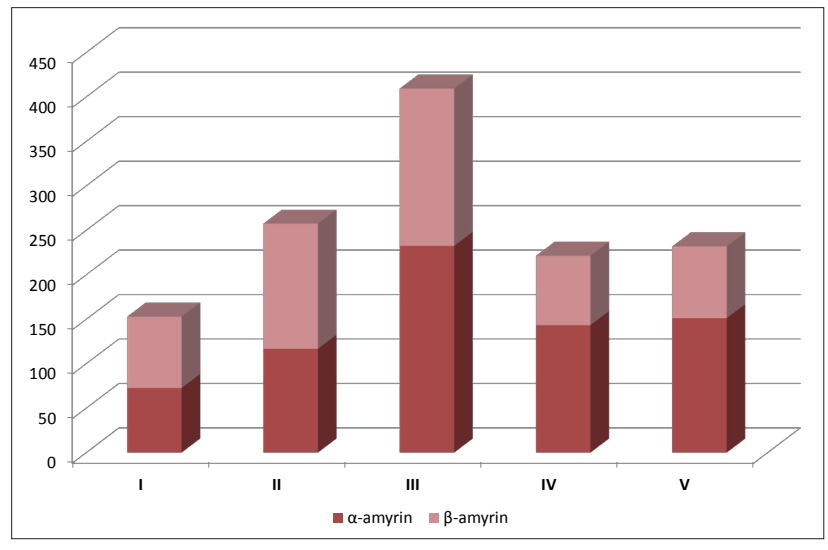

Figure 3. The comparison of $\alpha$-amyrin and $\beta$-amyrin content in different varieties of $H$. lupulus: I - magnost, II - magnum, III junga, IV - sybilla and V - lubelskis

\section{CONCLUSION}

High performance liquid chromatography with spectrophotometric detection (HPLC-DAD) was successfully 
applied for analysis of two amyrins in different varieties of H. lupulus.

The obtained validation parameters such as high linearity (correlation coefficient $r \geq 0.997$ ) and high precision (RDS $<1.70 \%$ and $<1.81 \%$ for $\alpha$ - and $\beta$-amyrin, respectively) occurred satisfactory for quantitative determination. Both $\alpha$ - and $\beta$ - amyrin were detected in investigated plant material. Their contents were from 72.7 to $232.5 \mu \mathrm{g} / \mathrm{g}$ and from 77.9 to $176.9 \mu \mathrm{g} / \mathrm{g}$ of dry herb, respectively. The significant variation of investigated compounds amount between varieties was found.

\section{REFERENCES}

1. Chadwick L.R., Pauli G.F., Farnsworth N.R.: The pharmacognosy of Humulus lupulus L. (hops) with an emphasis on estrogenic properties. Phytomedicine 13, 119, 2006.

2. Colgate E.C. et al.: Xanthohumol, a prenylflavonoid derived from hops induces apoptosis and inhibits NF-kappaB activation in prostate epithelial cells. Cancer Letters 246, 201, 2007.

3. Gerhauser C.: Broad spectrum antiinfective potential of xanthohumol from hop (Humulus lupulus L.) in comparison with activities of other hop constituents and xanthohumol metabolites. Molecular Nutrition Food Research 49, 827, 2005.
4. Jabeen, K. et al. Antifungal compounds from Melia azederach leaves for management of Ascochyta rabiei, the cause of chickpea blight, Nat. Prod. Res., 25, 264, 2011.

5. Schiller H. et al.: Sedating effects of Humulus lupulus L. extracts. Phytomedicine 13, 535, 2006.

6. Trojak-Goluch A., Skomra U.: Artifically induced polyploidization in Humulus lupulus L. and its effect on morphological and chemical traits. Breeding Sci., 63, 393, 2013.

7. Van Cleemput M. et al.: Hop (Humulus lupulus)-derived bitter acids as multipotent bioactive compounds. J. Nat. Prod., 72, 1220, 2009.

8. Wang X. et al: In vitro and in vivo antioxidant and antimutagenic activities of polyphenols extracted from hops (Humulus lupulus L.). J Sci Food Agric., 94, 1693, 2014.

9. Wansi J. P. et al.: Antimicrobial and antioxidante effects of phenolic constituents from Klainedoxa gabonensis, Pharmaceutical Biology, 48, 1124, 2010.

10. Yu L. et al.: Novel prenylated bichalcone and chalcone from Humulus lupulus and their quinone reductase induction activities. Fitoterapia 93, 115, 2014.

11. Zanoli, P. et al.: Evidence that the acids fraction of hops reduces central GABAergic neurotransmission. J. Ethnopharmacol. 109, 87, 2007.

12. Zanoli P., Zavatti M.: Pharmacognostic and pharmacological profile of Humulus lupulus L. J. Ethnopharmacol. 116, 383, 2008.

13. Zheng, Y. et al.: Antibacterial compounds from Siraitia grasvenorii leaves, Nat. Prod. Res., 25, 890, 2011. 